Citation: Mannion, G., Miller, K., Gibb, I. \& Goodman, R. (forthcoming 2009)

Reading Writing and Resonanting: striking chords across the contexts of students' everyday and college lives. Pedagogy, Culture, Society.

\title{
Reading, Writing, Resonating: striking chords across the contexts of students' everyday and college lives
}

\author{
Greg Mannion * \\ Kate Miller * \\ Ian Gibb $\dagger$ \\ Ronnie Goodman † \\ *Institute of Education, University of Stirling, Scotland \\ $\dagger$ Perth College, Perth, Scotland
}

\begin{abstract}
This paper draws on data from an ESRC funded research project on literacies in the context of further education in the UK. Taking a social view of reading and writing moves us away from seeing literacy (singular) as a universal set of transferable skills towards seeing literacies (plural) as emergent practices found in social settings. Taking a situated, socio-cultural approach also leads us to notice how contexts and practice co-emerge. The research project we document sought to inquire into the interface between literacies in students' everyday lives and their formal college coursework. Findings indicate that if contexts and their associated literacies are co-emergent and co-determined by each other, then literacy skills do not simply 'transfer' between contexts but are better seen as resonant across contexts through the manner in which discrete aspects of literacy practices relate. We conclude by delineating some strategies for enacting a critical, situated-yet-polycontextual literacy pedagogy that pays respect to students' everyday literacies as a valuable resource base in formal coursework.
\end{abstract}




\section{Introduction}

Designing a website for a music band, reading biographies of famous people, collecting sports team memorabilia, doing a report for a charity: all of these were the everyday, lived literacy experience of students in further education that we encountered on a research project we describe herein. Seeing literacy as a situated, local and everyday practice directs our attention to the rich diversity of reading and writing within its social context. Anthropological and ethnographic studies have for some time been successfully describing the situated nature of literacy practices of everyday life in a number of contexts (workplace, home, leisure, community) (Barton \& Hamilton, 1998; Barton et al., 2000). Taking a contextual and critical view, this approach leads us to ask questions about these 'literacies': who is doing what, with and for whom, how, when, where, why, with what technologies, under what conditions, and with what values, attitudes and beliefs. This contextualized view of literacy has been captured through the theoretical constructs of 'literacy events' (for example, writing an individual email), 'literacy practices' (for example, routine use of e-mail among colleagues) and the context for these practices within 'domains' (for example, the workplace) (Barton \& Hamilton, 1998). Critically, Barton et al., (2000) note that social organization pattern literacy practices so that some are rendered more dominant, visible and influential than others.

The 'situated' perspective challenges the more prevalent view of literacy as a set of decontextualised skills that are easily transportable across contexts and re- 
engages us in debates around 'transfer' and skill acquisition in education.

Drawing on these perspectives, we explore how educators might draw upon this rich everyday source of literacies and we provide a framework for understanding the connection between literacy practices across domains when one of these domains is a formal educational context. The data we use comes from a three year research project, Literacies for Learning in Further Education (hereafter, LfLFE) that was funded as part of the United Kingdom's Teaching and Learning Research Programme (TLRP), administered by the Economic and Social Research Council (ESRC). The LfLFE project involved collaboration between two universities University of Stirling and Lancaster University - and four further education colleges in Scotland and England. The premise for the project was that the literacy demands and practices of F.E. colleges are not always fashioned around the resources people bring to student life and, crucially, the potential for greater interaction between these literacies. Other publications arising from the project have looked at, for example, the methodologies employed (Mannion \& Ivanič, 2006), the literacy practices of students in their everyday lives within and outside college and the contextualised literacy practices required by different courses of study (for example, Satchwell \& Ivanič, 2007). The focus here is look in more depth at some cross-contextual empirical data and a theoretical understanding of how literacies are relevant across contexts.

The article begins with an exploration of theoretical orientations for the project. It goes on to introduce the key analytical tools devised before reporting data from two student case studies. We close by suggesting that it is a central pedagogical challenge 
for lecturers and students alike to notice how and when reading and writing can afford resonance between contexts.

\section{Theoretical Debates}

The premise of our research was that socially embedded literacy practices, and not just written texts, are worthy of ethnographic investigation. This theoretical position, sometimes called, New Literacy Studies (hereafter, NLS) (see Street, 1984 for an early exploration) suggests there are many 'literacies' and that these vary from one context to another. The construct of 'domain' is important here with earlier researchers setting out to look at how literacices were 'situated' in contexts such as home, school or workplace. 'Literacy domains' are the relatively stable, structured, patterned contexts within which literacy is used and learned in distinctive discourse communities (Barton et al., 2000). However, as Barton \& Hamilton (1998) assert, literacy domains are not permanently bounded, but suspected they were likely to be permeable and overlapping. Of late, there have there been a number of empirical studies that explore how teachers might connect up formal and non-formal literacy domains (for example, Marsh, 2003; Millard 2006). Millard (2006) argues for a transformative pedagogy employing a 'literacy of fusion' through drawing on students' own 'funds of knowledge' (Moll et al., 1993) to get students to create personally meaningful texts. Across this work, while this principle of drawing on students' everyday knowledge is commonly advocated, it is not clear 'how' this process works or what theoretical understandings might explain it.

\section{From Transfer to Recontextualisation}


One background theoretical debate here concerns the issue of 'transfer' in teaching and learning: if a practice is learned and situated in a context, how does it 'transfer' to another context? De Corte (1999) reminds us that some versions of situated cognition assert that knowledge and skills will not transfer between contexts because they are so strongly embedded in and tied to the context in which they are acquired. In response, there has been a move away from 'container' notions of context ('strong' situatedness) and cognitive concepts of transfer (decontextualised notions of transferable skills) towards more relational views of contexts (Ivanič et al. 2004). Boundary-crossing and border-crossing, polycontextuality, and boundary objects (Tuomi-Grohn \& Engeström, 2003; 2003a; Engeström, et al., 1995; Star \& Griesemer, 1989) are some of the constructs that are mined in the effort to capture a socio-cultural understanding of learning across contexts but these were not easily applicable to literacy practices or the data we were encountering in LfLFE. Recontextualisation (Van Oers, 1998) did offer a viable sense of how learners generalise from one context 'into' another since what they are doing is using meanings from previous contexts to meet new ends. In this view, learning is akin to a recontextualisation of familiar practices which are reshaped through engaging in a new activity in response to constraints and affordances of a new situation. For LfLFE, we set out to discover how embarking on a course of study might be configured so that learners could recontextualise their own semiotic experiences (Usher \& Edwards, 2007) (or people's use of 'signs' in the widest sense of meaning making and taking in a material world). Semiotic practices will include what learners read and write but also the context for these literacy practices (how they dress, what gestures they employ, their experiences of cultural signs found in film and radio and so on), all of which operate across the various domains of leisure, work, home and college. 


\section{Learning as 'Becoming' and 'Design'}

Learning as recontextualisation has wider effects. Because the recontextualisation of experiences across domains will involve meaning making and meaning taking, the processes involved are likely to involve both personal investment and transformation of semiotic resources. In part, this is because when more than one context is in play (or multiple 'activity systems' - see Russell, 2005) people will encounter contradictions among the different features of these contexts. Handling these contradictions encountered through recontextualisation will have consequences for identification and learners' dispositions. Hodkinson et al. (2008) argue that people 'become' through learning in one situation and must do so again in a new learning culture taking on new dispositions as they do so. The two student case studies will explore some of these contradictions in practice.

Usher and Edwards (2007, p. 6), building on Lave (1996), offer one view of learning as changing our understanding in practice through participation in everyday life. They suggest learning is a socio-culturally situated and semiotic process that is “enabled and constrained by a person's socio-cultural understandings, the meanings taken, of his or her place in a social process as well as by the materiality of their condition". Kress (2001) and the Multiliteracies group (Cope \& Kalantzis, 2000) use the term design to describe a similar process of recontextualisation through literacy: they suggest that we continuously re-read and re-write both the world and ourselves. Ivanič (2004) supports this view arguing that through the intertextual processes of all communication we take on new social roles, values and beliefs. As Kress (2001) puts it, inner sign making helps shape the subjectivity of the signmaker while outward sign 
making can create new forms of syntax or text (which can recursively impact on one's subjectivity). By this understanding, learning is about transformative engagement in the world and of the self and of the resources of representation (Kress, 2005; Leander, 2002; Usher \& Edwards, 2007). The implications for the learner's role in learning as design work are drawn out further here by Kress (2005). This view suggests that the acquisition of literacy skills and their transfer is untenable:

Design focuses forward; it assumes that resources are never entirely apt but will need to be transformed in relation to all the contingencies of this environment now and the demands made. The focus on transformation rather than on acquisition makes the designer agentive-in relation to existing socially and culturally made resources, social environments in specific, with the designer's interests in this occasion of design and in relation to that audience (Jewitt \& Kress, 2003).

(Kress, 2005, p. 20)

\section{Identification Through Literacies}

We have posited a view of learning as 'design work' involving the recontextualisation of semiotic resources and the acquisition of new learner dispositions across domains. As practices change, identifications alter, and understanding/meaning are generated. This means our research has sought, in part, to understand identity formation through engagement in literacy practices across contexts (see also Ivanič, 2007). Hall (1996) offers a useful and 'polycontextual' theory of identity formation that can be of use here. He sees identification as a continual process of transformation that is not unified but fragmented and distributed across contexts, intersecting practices and discourses. We were keen to understand how students see literacy practices as vehicles for connecting with students' sense of 'who they are' or 'who they want to become'. Because we continually struggle to identify across contexts in any one moment, 
recontextualization is seen as the process of participating in any number of contexts while concurrently changing that context through making sense of it out of experience of other situations, past and present and making new sense of ourselves. We sought to explore if and how these polycontextual processes would be rendered visible or understandable through the lens of literacy. Learners "as meaning-makers are always uniquely transforming and recombining communicative resources for their own purposes, and thus constructing subjectivities for themselves which do not necessarily conform to type" (Ivanič, 2004, p. 306).

\section{Border Literacies and Bordering Literacies}

We have argued that semiotic practices, including literacy practices, are not just statically embedded in container-like contexts then but are continually produced through the way people, practices and their contexts emerge over time and are affected by other contexts (Chaiklin \& Lave, 1996). Clearly, practices found in an earlier situation are drawn upon in some way in new situations; how this works for literacy practices was our concern. At the onset of the project, our aim was to identify those 'border literacies' that we suspected would enable people to negotiate successfully between what we termed informal vernacular literacies and the more formal literacies within the FE context and that positively affect learning outcomes. Intuitively, we hoped that discrete literacies might function as boundary objects (Bowker \& Star, 1999). However, we did not find wholly distinct literacy practices which could be harnessed in their entirety as resources for learning in that way; this finding marries with the theoretical position that practices and contexts emerge in a coupled way and are effect each other reciprocally. Firstly, 'border literacies', as static entities do not exist as they are wrapped up in their contexts and are part of the 
design work students engage in for that context, so they cannot be transported across contexts; secondly, since all literacy practices were emergent, they were all 'bordering off' more than one context all the time. To seek to grab and deploy discrete practices (such as 'website design' or 'diary keeping' or 'MSN') from the everyday domain of students' lives and somehow 'place' them into college coursework as resources for learning would, therefore, be a crude strategy. This approach could in fact lead to an unthinking use of multimodal communication for its own sake, the tokenistic use of teenage magazines as sources, or a cursory and in appropriate use of new technologies.

A better question was to ask how all literacy practices 'border off' one another, along what dimensions and under what circumstances and with the generation of what meanings? This approach fitted well with Leander's (2002) view of literacy 'domain' as emergent. Here, literacy practices are both dependent upon and productive of multiple domains. Literacies, like all practices (see above), may be situated but they also evolve with and through the generation of (more than one) context. Our shift towards understanding contexts relationally made it more obvious that learning was mediated through social practices and objects (see Edwards \& Fowler, 2007, for a fuller discussion) and brought a focus on the meaning making abilities of learners as they strove to communicate through transforming materials and ideas found in their semiotic landscape for their own purposes.

\section{Aspects of Literacy Practices}

In order to find leverage on our research question about how to draw upon students' everyday literacies in coursework, our strategy was to try to unweave the component 
strands of a given literacy practice within its context. Through the analysis of the data from almost 100 student's case studies across 12 subject areas (examples of some of this data come below), we generated a set of elements or aspects that appeared to be present for a given literacy practice. We suspected that it might be these aspects that generated the affordance for connectivity across contexts. As we took on board that literacies and their contexts are co-determined, we noticed how some aspects were found to be more critical in creating the links across these emergent domains. Later, by paying attention to these critical aspects in the action-inquiry phase of the project, lecturers sought to fine-tune or re-calibrate these subtle aspects of literacy practices in order to render elements of curricula more relevant across domains. As we will show, a relational and polycontextual analysis suggested that literacies do potentially 'border off' each other across multiple domains (of college, home and work, leisure and other spaces) in ubiquitous ways. As meaning making in any new emergent context is itself novel, and since contexts themselves are ever changing, only some aspects of emergent literacy practices could be co-aligned with aspects of literacy practices from previously experienced literacy events. This was a critical insight in explaining how literacy practices border off each other in various ways. In figure 1, below, we list the possible aspects of any given literacy practice that could be critical in engendering connectivity across domains, connecting literacy experiences across various literacy events. (See also Ivanič et al., 2007, for an alternative account of these aspects - or 'elements' - and their derivation). 


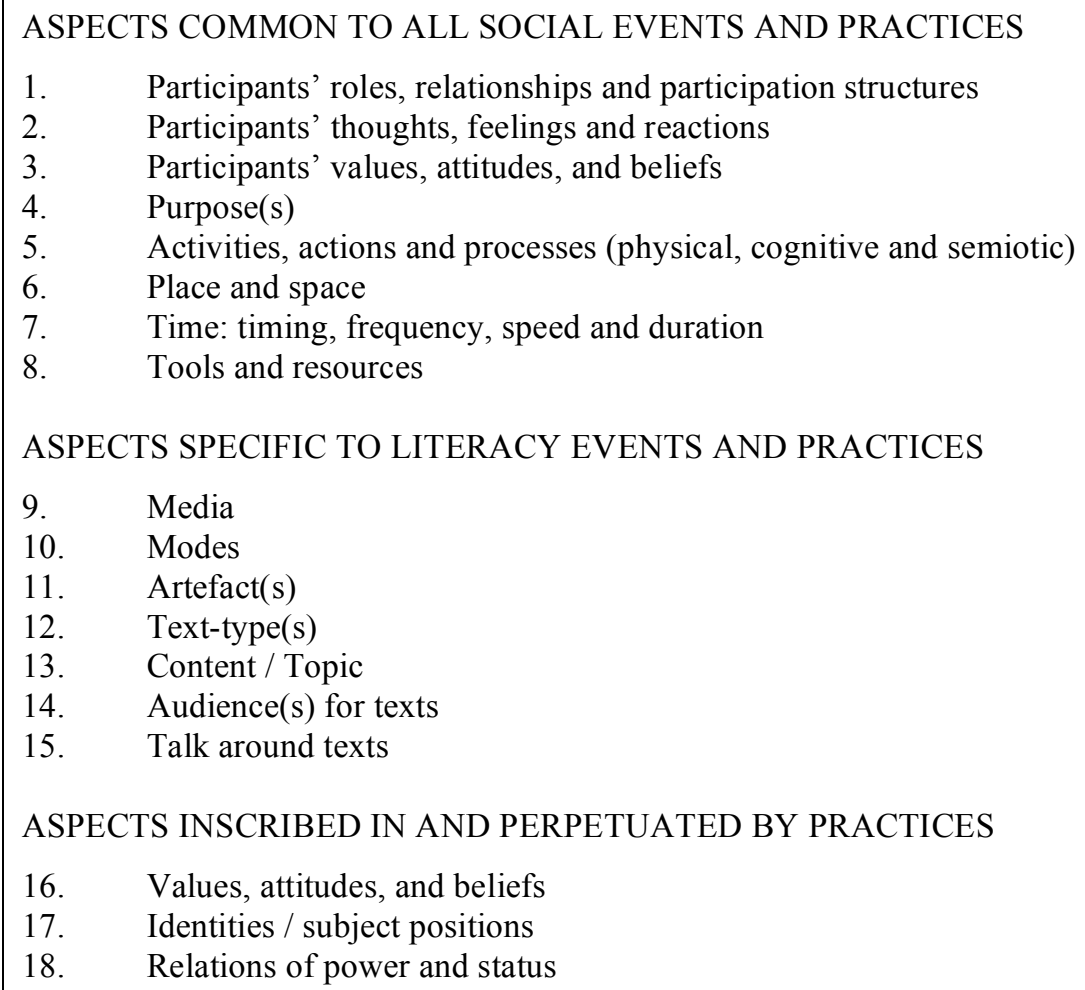

Figure 1. Constituent aspects of literacy events and practices.

\section{Resonance through literacy}

The term we will use to describe the connectivity or alignment between aspects of practices found in different domains is resonance. We will explore what we mean by the resonance of literacies next. As the cases will demonstrate, it was the contradictions and consistencies between the aspects of literacy practices found in different domains that explained how participation in a formal educational setting was experienced positively and / or resisted. The term resonance helps us capture this nuanced approach.

Resonance is a term from the field of music, one of our researched subject areas. We know from music that two notes may be resonant but be different. Resonance therefore incorporates notions of consonance (sounding together) and dissonance 
(sounding apart) akin to the idea of some aspects of reading and writing being consistent and inconsistent across domains. Resonance in literacies is suggestive of a non-linear view of the achievement of a form of 'transfer' of literacies across contexts through the emergence of contradictory aspects as well as consistent ones. The term is useful because it flags culturally sensitivity: like literacy, music is harmonious to the ear in different ways in different cultures. Resonance, therefore, captures the idea of relations between phenomena that are differently located (say two instruments in a room playing different chords). Its application to literacies describes how aspects of reading and writing practices can be recontextualised or attuned to in subtle ways so that they have a relationship with other literacy practices. This recontextualisation or attunement does not involve the migration or wholesale transfer of any easily identifiable skills or 'border literacies' but rather the attunement of aspects of these. Resonance is powerful as a metaphor because it allows us to hold on to an emergent and relational view of literacies, their situated nature and their power in affording new opportunities for identification, while yet accounting for how different domains might relate via literacy (see also Mannion, 2006; Goodman et al., 2007; Ivanič et al., forthcoming 2009). In a more fine-grained and thicker description, we next explore what 'literacy resonance' meant for two students.

\section{Icon Mapping as a Method}

The methodology that informed this project was broadly ethnographic, hermeneutic and reflexive (see Mannion \& Ivanič, 2006). In phase 2 we sought to document students' everyday literacies. One method (of a number) that set out to capture this data was the 'Icon Mapping Exercise'. The rationale here was to explore students' own understanding of the inter-related process of learning, recontextualization and 
identification across context. For this method, a set of 40 'icons' were presented to students. These, in semiotic terms are in fact symbols that could be interpreted differently by each respondent to denote the sorts of literacy practices and events they wanted to discuss (see figure 2). Piloting allowed us to refine the icon set to reflect the sorts of activities students found relevant. After piloting, we realized the method allowed respondents to fruitfully explore how these processes relate through the lens of literacy, perhaps in part, because the respondents had already become quite 'literacy-aware' through participation in earlier fieldwork.
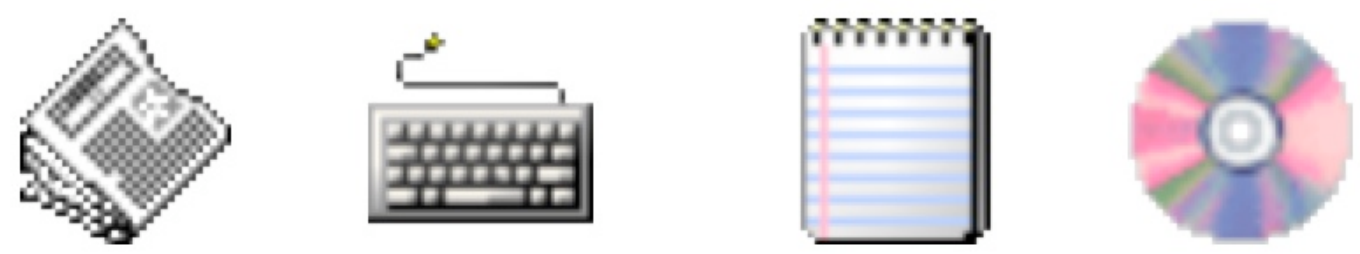

Figure 2. Examples of icons used.

The icons, as we used them, came in some way to represent the resources found in what Kress \& Van Leeuwen (1996) calls the semiotic landscape of learners' lives. In this method, they were invited to do some design work (Kress, 2001) albeit symbolically. Individually, they were invited to pick a range of icons that reminded them of the sorts of reading and writing that they engaged in their daily lives inclusive of those encountered at home (actually in the home or as part of students' leisure time), outside home (in workplaces / placement / part-time work), or in college (in / outside class).

In order to generate salient data, the interviewer asked respondents to remember times and places where reading and writing felt 'really important' to them, being those that they 'would miss if they couldn't do them any more', were very 'meaningful' for them, or had led them to 'understand and learn' things that were important to them. 
These selected icons - now acting as signs or referents to valued literacy events and practices - were explored for their relevance. Thereafter, respondents placed or 'mapped' these icons onto a piece of flip chart paper into any one of the areas of three interlocking circles (loosely denoting 'home/leisure', 'college' and 'work' domains) according to any of the following guide criteria: (a) where they take place, or, (b) for whom or for what 'place' they had most relevance. The use of a three circle Venn diagram mean that literacy practices that were relevant across more than one domain could gain cross-domain significance allowing us to explore the polycontextual nature of literacy practices as appropriate through probing. Tape recordings were made of the conversation, a record was kept of the icon map and a digital image of the map was made. Interviews were transcribed in full and/or summary notes were written up.

\section{Findings}

Looking across 11 icon maps constructed (across 6 subject areas) we found evidence of a high degree of cross domain relevance of a very large percentage of the types of reading and writing deemed important by students. In fact, the majority of all icons in the 'college' domain (34 out of 47 icons selected) were placed in the overlapping sectors with home/college or home/work/college areas. There was a relative absence of icons relating solely to 'college'. From this, we can say, that literacies did have strong ubiquitous or 'normal' polycontextual significance and that home/leisure and work domains were indicative as more 'important' to many students. More importantly, through triangulation with our other methods, we began to see that there was a lot of potential for college-based reading and writing to be more connected to with the sorts of literacies students' valued in other areas of their lives. We did notice that the everyday literacies that were valued by students tended to be multi-modal, 
(combining symbols, pictures, colour, music), multi-media (combining paper and electronic media), shared, (involving interactions, participation and collaboration), and employed non-linear reading pathways. They were also experiences that allowed students to have quite a lot of control over these events and were clearly purposeful for them. These communications often had a clear audience, were generative of new ideas or knowledge and involved degrees of self-determination in terms of activity, time and place. They were also varied and not repetitive (see also Ivanič et al., 2007; Kress, 2005). A look at two particular cases will explain this more fully.

\section{Two Student Case Studies}

\section{Student 1}

Two students' icon maps will be explored as examples of this data. First, we take Stephen who is an Intermediate 1 catering student.

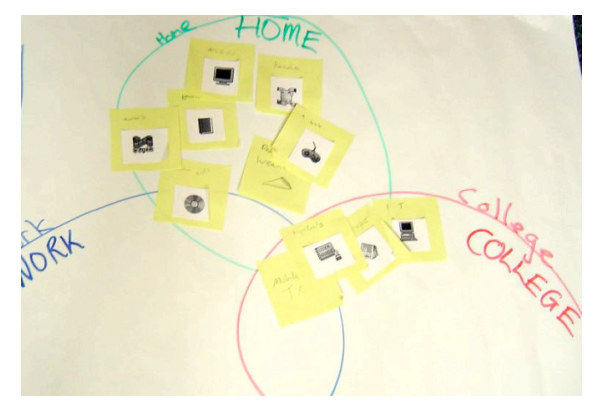

Figure 3. Stephen's Icon Map. Home: Surfing net for information / 'personal research'; downloading tunes; burning CDs; playing X Box; using website to 'share' tunes etc via the 'Kazaa' website; reading fiction. College/Home Overlap: Using IT; reading newspaper; reading handouts; using mobile phone for texting.

Stephen's map (like many others) revealed the dominance of his own leisure and home-related literacy practices over formal course-related literacy practices. More 
important is the manner in which the home / leisure related literacy practices are valued above those related to college coursework particularly in his discussion of the map. He feels that many students his age share the same interests which he summarises as: "having fun, playing games, texting, computers". Aside from 'handouts', not many of the other icons seem to have immediate relevance for the catering course. 'Mobile phone', 'message texting', 'reading the newspaper' and 'internet use' are connected to his college domain merely because they can happen in either place or because the college provides good internet access.

Stephen is an avid user of new and old technology of certain kinds for communication. The literacy practices he deems important include MSN instant messenger; telephone texting and peer-to-peer file sharing. File sharing (mainly on 'Kazaa') is a central activity for him: he can share and download audio/music, games, software and video files, and ideas for how to 'cheat' on computer games. He also burns 'tunes' onto CDs and onto his X Box so he can play music while playing games.

Stephen reads The Sun newspaper and shares his thoughts about the news with others in college. He does not like TV.

S: I don't really like the TV eh, because most of it's pish ken so I dinnae watch $\mathrm{TV}$ at all really

GM: And what's better about the newspapers then for you?

S: I don't know, you can do it whenever you want, the news is always on at a certain time an that eh, so you've got to be in for it and that eh? And then I mean you can watch BBC News 24 or that but that's just a load of pish. 
For leisure, he plays a lot of computer games. He also reads a lot of fiction, getting through about 'a book a week'. (David Gemmell, Catherine Cookson are examples of the authors he reads). He mostly borrows these books from his grandmother. Stephen's almost apologetic or embarrassed when he notices that he reads more fiction than the interviewer which reveals something about which literacies are dominant or more valued:

GM: You read a lot more fiction than I do by a long shot.

S: Yo, that's well bad. You're making me feel like a geek now.

He sees handouts as a central way of keeping abreast of college work. He feels reading handouts at home when he can find time enables him to pass the course. He also engages in what he calls 'personal research' via internet searches on topics that interest him. For example, he told us that he found out on the internet that cannabis burns at a higher temperature than cigarette tobacco and because of this there is an increased risk of throat cancer.

He notes that communication on campus might be improved on campus if there were a MSN-type system in place. He feels the current e-mail system is not instant enough and it is solely for use in the college, a practice that perhaps supports the finding of a lack of connection between the 'college' and other domains. On reviewing other possible connections between everyday literacy and college life, he went on to suggest that there could be music playing while they worked in the kitchens. While he finds essay writing very tedious, he would find it a lot easier to work with various sorts of multi-media for an assignment than traditional paper-based linear texts: 
S: [...] Write an essay or burn a CD? There you go [he gesticulates the sort of work he would do on the computer with a series of quick hand movements and then offers me his finished product in mime]: CD! Oh ... but writing an essay! I cannae be arsed writing this $\mathrm{f}^{* * * * * *}$ essay. Oh my God, [that would be] such a load of $\operatorname{sh}^{* * *}$ !

Reviewing his map he comments: "young people are more interested in what they do at home than what they do at college eh, like it's more important to them cos they really want to do it" whereas at college he feels students get involved in reading and writing because they "need to".

\section{Student 2}

The second case is Laura, a Music student. Laura claims music is the love of her life. She is a member of bands some of which are part of the participation in the course.

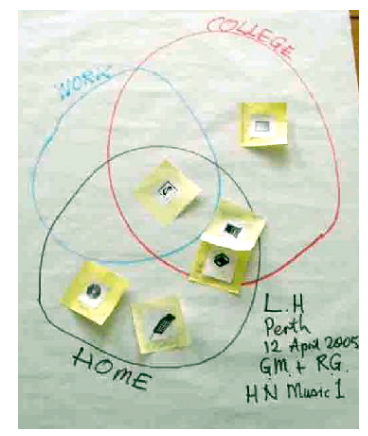

Figure 4. Laura's Icon Map. Home: Texting, playing and reading music, playing CDs. Home / College Overlap: Using computer, reading books. Home / College / Work Overlap: Writing Lyrics. College: Taking notes (and writing assessments).

A key text is her 'song book'. This is a focus for her own creative writing is a centrepiece for her literacy (placed in the centre of the map). 
Laura: I love writing lyrics and stuff it's my way of, [I] suppose, of getting my emotions out.

She sees the activity of writing and doodling in here as being related to her college course and her future career in the music industry: she eventually wants to be a singer / songwriter. The literacy practice of writing songs and lyrics sometimes starts with a melody or some lyrics. She often gets these down on the notebook and this can happen almost any time of the day like when she is doing the ironing for example. She draws pictures in it too. Once there are some lyrics in place, she will get the guitar out and try to work out some chords for these pieces. The lyrics are the important part of the product for her but these records in her notebook are reminders of the melodies that she creates for them too. She tends not to get into writing a full score (inclusive of rhythms and stave notation) for these songs but is prepared to consider the usefulness of being able to do this.

Laura downloads music from her CDs and catalogues them on her computer according to genre or 'type'. Then she can search for and find music categorised under various terms some of which are her own terms rather than the generic ones found in music stores such as soul, classical etc. She also pulls lyrics for songs she likes off the web and then reads the lyrics and sings along to them.

Laura loves reading books; she reads books, often related to the music industry (musician's biographies, for example) as a way of relaxing most nights. Sometimes her parents suggest these texts, while others are sourced through reading about them in magazines. Book reading is an important practice: 
Laura: I'm learning and I enjoy learning, even when it's fiction or non-fiction. [...] I like reading books like the Marley book [No Woman, No Cry] because it's showing how people got into the music business but also I've got another book, well it's called Popular Music. It's a fiction but I haven't actually read it yet, just started reading it but it's about the person's love for music or something.

There is an overlap between 'reading for leisure' and 'for college work' in that she sees how they are helping her learn. There are differences in how her reading and writing were sourced, how 'hard' she found them, and who owned them. In the evenings for leisure, she reads her own purchases while more research-led reading for the coursework is borrowed from the library. Recommended course texts seem 'hard' and she's not read many of them or if she starts, she does not 'get through them'. She thinks reading fiction could be a good component of a course. She prefers book reading to internet surfing and looks at web sites only a couple of times a week when in college as she has no internet connection at home. She says she would miss internet access however if she didn't have it through college.

Laura also takes notes on what lecturers say in class. She usually writes her own full sentences for this rather than short notes. Unlike handouts, that tell her what she is 'supposed to know' [Laura], the note taking practice is about the creation of personal meaning rather than an exact record of what the lecturer said.

GM: Yeah, ok and the reason why the note taking is important to you is because?

Laura: I'm learning. [...] 
GM: $[\ldots]$ do the notes feel different to, let's say if the lecturer gave you a transcript of what they said or gave you hand outs are they different?

IEE: Emm yeah, because when I'm writing it I know exactly what I mean by it.

Laura's notes are carefully filed in plastic sleeves and then placed into bigger folders. Her notes are the sources of longer pieces of writing that emerge in her essay writing which she does on a computer. She feels that if students could see the relevance of what the essay 'does' in terms of helping them with the subject area, that it would be less onerous and more engaging. This area of her literacy seems somewhat unconnected to literacies in her 'out-of-college' life though perhaps her lyric writing is similarly generative for her. She does not appear to have been actively taught explicitly how to do these things as a student. She notes that the computer is a central player in her literacy but she tends to think of it as something she actively resists by handwriting in her song scrap book.

Laura texts people a lot and her phone is 'always on'. She uses a lot of short cuts when constructing texts. Texts tend to be about arrangements to meet friends. She thinks that if the college started sending texts to students (say if a lecture was cancelled), they would get read 'straight away'. In contrast, she has never sent an email to a tutor or teacher at school. She feels e-mails are for family and friends at a distance and takes the place of letter writing as a practice. Texts are 'for friends' she meets every day - they don't usually discuss college work - while live on-line chat via MSN is not something she does much of (perhaps because of not having access to 
internet at home). When she was abroad for 6 months, the Internet provided her with a very important 'lifeline'.

College 'work' is sometimes done in a notepad, sometimes on computers and this happens at times in college and at time at home. Revision may happen in the library or she sometimes seeks out a place to study in the college. This aspect of her writing seems separate enough from her home and other contexts except that it may happen spatially at home at times. In general, she values more the products of her 'own' writing and reading: "people just need to [write and read] instead of having it as something that you have to do, I think people need to realise that it is something that will help them".

\section{Analysis}

There were clear dissonances and consonances (or contradictions and consistencies) or between the domains home, college and other contexts (such as work and leisure). How each student's participation in the formal educational setting was achieved and / or resisted can, in part, be explained by reference to how the aspects of the course's literacies were experienced as resonant across the students' other contexts. Both are 'literate', but differently so. Coursework that had literacies and contexts within which resonance could be sufficiently felt or attuned to by these students, was likely to be more engaging. We wanted to understand how. In the following analysis, the aspects from figure 1 (above) are italicized.

We discovered that different timbres of literacy resonance were experienced by students through the ways in which aspects of literacies worked. Resonance was 
engendered through the ways in which coursework literacies were valued, what the actual content of the texts was about, how the communications were mediated, what audiences were addressed and what identifications and purposes were relevant. For Stephen, we can say there is a lack of resonance between the literacies he located in the 'everyday' and those found more formally in college. For Stephen, listening to music, playing computer games and doing 'personal' research on the internet were not placed on his map in the college domain because he felt they are not valued at college (or as he put it "important"). For Stephen, we notice the irregularity of affordances offered by college coursework for engaging in the sorts of communicative practice that he valued.

The kind of reading and writing he 'likes' and finds purposeful is not the kind of thing that he does at college or, at least that is how he sees it. There were well-defined differences between the literacies that afforded identification within Stephen's affinity groups and those that afforded identification as a student chef. Similarly, the audiences and media he employs for these communications are not resonant with college-based reading and writing. For the moment, the literacy practices that are important to Stephen - texting, having fun, playing games and computers - are not generally resonant with the literacies found in the catering course.

Laura too talks about literacy practices that reveal a high degree of personal ownership and commitment. Yet, unlike Stephen, a range of Laura's literacy practices appear to afford resonance between her more personal home domain and that of the college. But her 'important' literacy practices are intimately connected to an identification that is course-related: she is and wants to become a songwriter or 
musician. The resonance between her literacy practices in different domains enhances viable subject positions with the music industry within which she is playing an increasing role: being a music student, a musician in a band and a lyricist are clearly connected. One obvious literacy practice - lyric writing - serves an overlapping purpose of communicating with 'her' audiences allowing her to relate learning, identification, and multiple contexts. Similarly, we note that reading works of fiction about musicians too potentially helps her make connections between 'Laura-at-home' 'Laura-at-work' and 'Laura-at-college' whereas, for Stephen, fiction reading seems unconnected in terms of the content or topic (another key aspect of any literacy practice). For Laura, understanding the practice contexts of the music industry, learning how to write songs and develop one's creative abilities and 'passing the course' all allow Laura to (in terms of literacy) negotiate a viable polycontextual learner-musician identification.

Laura and Stephen are, each in their own way, undergoing a process of becoming (Hodkinson et al., 2008) through literacy practices. They were also recontextualising (Van Oers, 1998) literacies in their own way using the semiotic materials they value or encounter (see Kress, 2005). Both of these students are engaging in literacy practices that are locally relevant for them and these have relevance with college practices in different and subtle ways. Some literacy practices appear to engender resonance across contexts while others seem more separated off. In other words, some literacies afford strong degrees of polycontextuality (or have that potential) and enhance learning while others may not. We have found the term resonance to be useful in capturing how aspects of these literacies were critical in this connectivity. In summary, we found that literacies were resonant (inclusive of consonance and 
dissonance) to varying degrees across domains and these resonances were felt through aspects of literacy practices encountered in other domains.

\section{Attunements}

Within LfLFE, the last action-oriented or intervention phase set out to explore how educators might try to enhance the resonance of the literacies experienced on and of courses by students. Lecturers worked alongside research team members to document data on 'understanding in practice', their effects on staff and students, and their related pedagogical understandings. Most found that altering college literacies to allow for greater resonance with students' everyday literacies was not a simple task as they also had to keep a 'weather eye' on the core requirements of the units taught. Importantly, we found that lecturers and students across the board were initially unaware of the extent, depth and sophistication of their students' vernacular literacies. Once an understanding of this was developed, the tutors did, however, find effective ways of fine-tuning aspects of literacy practices on their courses to achieve a critical degree of resonance across key aspects of students' everyday literacy practice (see Ivanič et al., 2007; Ivanič et al., forthcoming 2009). For example, a music lecturer changed the medium of an assessment by requiring students to do digital web-based biographies instead of cvs (see Goodman et al., 2007). Another tutor worked with the aspects of audience and modality through encouraging students to consider the formal $\log$ books of assessed progression more as personal narratives with images to be shown to prospective employers (for further examples and a holistic account of the project see Ivanič et al., forthcoming 2008). Critical pedagogical practice, therefore, was about re-calibrating some of the aspects (see figure 1) of literacies on courses so that they were more resonant with the literacies students already understood and 
valued in their situated contexts. This needed to be achieved while still attending to the needs of other contexts such as the college requirements for assessment and employers' interests.

Our analysis of students' literacy lives leads us to confirm traditional, competenceinformed ideas of transfer and neatly bounded views of literacy as transferable skill are not viable or accurate (see Edwards \& Fowler, 2007); core / key literacy-related 'skills' are not transferred. Instead, communicative practices involve recontextualisation and enactment in emergent contexts through drawing on traces of previously experienced contexts. Considering the role of aspects of literacy practices is useful in making this process explicit.

We are suggesting that critical pedagogy through literacy is possible though is not an exact science; it is rather a tricky situated practice negotiated between learners, lecturers and the semiotic resources available and deemed appropriate to the learning tasks in hand. Lobato (2003) suggests we redefine transfer as the attunement to the affordances and constraints of the material artefacts and social environments that are invariant between the learning context and the 'new' situation. This process of attunement sits well with our suggestion that literacy transfer can be afforded through attending to the aspects of literacy practices (audience, purpose, identification, etc listed in Figure 1). This form of critical situated-yet-polycontextual literacy pedagogy required in-depth knowledge on the part of the lecturers of their students' everyday literacies and an awareness of what new approaches might afford greater and useful resonance. But, it is learners that in part determine how relations across situations are ultimately enacted or performed; learning through literacy will involve learners in 
designing how the new literacies and their contexts get played out. Since students' diverse semiotic resources and experiences differ, and since the literacy events constructed for students' participation can always be resisted, learning can, therefore, never be pre-determined or assured as our cases expose.

Taking a socio-culturally informed, actor-oriented view of transfer leads us to ask new and better questions about learning, reading and writing as dynamic and creative processes. This is in line with the idea of learners as designers (Kress, 2005) and as recontextualisers (Van Oers, 1998) going through a process of becoming (Hodkinson et al., 2008). Opportunities for connections across contexts must first be noticed by staff and students, and be made an explicit part of the pedagogy before polycontextual design work can begin on the available and critically relevant semiotic resources. The lecturer / teacher, therefore, plays a key role here through building on students' dispositions while the learner plays a key role through noticing literacy relevance and new potentialities.

We hope practitioners and researchers alike will find critical purchase in these ideas and refine them through further inquiries and pedagogies. Perhaps there is scope for understanding the aspects of literacy practices (figure 1) as the malleable design elements that allow various literacies to inhabit more than one social world, rendering them plastic enough at times to meet local needs in more than one domain (Bowker \& Star, 1999; Star \& Griesemer, 1989). Because aspects of literacy practices will need local attunement, we advocate loose working arrangements for literacies that are not imposed on a group as they must appeal to the insiders of local cultures. Emergent 
literacies cannot be easily pre-determined but are at best 'designed for' (Christensen, 2005) by this view. The form of critical pedagogy via literacy we are envisaging, may not sit well with a literacy-as-skill, content-driven or transmission approach to curriculum as the critical aspects of the literacy practices may be too fixed to allow for the recontextualisation we envisage. As should be clear, we are not advocating a programmatic curricularisation of 'home literacies', a worrying process noted in other educational sectors (Marsh, 2003), since the connectivities across domain need to work both ways for all parties so that multiple meanings, valuations and audiences and the like are afforded scope for expression. Given that the practice of teaching, learning and assessment in FE and other sectors are often either seen as circumscribed by so many control mechanisms, these warnings and concerns are perhaps pertinent.

\section{Acknowledgments}

This article arises from work done within the Literacies for Learning in Further Education research project, funded by the UK's ESRC funded Teaching and Learning Research Programme (grant number RES 139-25-0117). Thanks are due to other members of the research team for supporting the development of the ideas herein. See www.lancs.ac.uk/lflfe for further details. We are also grateful for the comments made by two anonymous reviewers.

\section{Correspondence}

Contact details of corresponding author: Dr Greg Mannion, The Stirling Institute of Education, University of Stirling, Stirling FK9 4LA, Scotland. Tel: 01786 467614. E-mail: gbgm1@stir.ac.uk

\section{References}

Barton, D. \& Hamilton, M. (1998) Local Literacies: Reading and Writing in One Community. London: Routledge.

Barton, D., Hamilton, M. \& Ivanič, R. (Eds) (2000) Situated Literacies: Reading and Writing in Context. London: Routledge. 
Bowker, G. \& Star, S. (1999) Sorting Things Out: Classification and its Consequences. Cambridge, Mass.: MIT Press.

Chaiklin, S. \& Lave, J. (Eds) (1996) Understanding Practice: Perspectives on Activity and Context. Cambridge: Cambridge University Press.

Christiansen, E. (2005) Boundary objects, please rise! On the role of boundary objects in distributed collaboration and how to design for them. Paper presented at workshop 10 'Cognition and Collaboration', CHI2005 Portland Oregon, April 2-7, 2005. Available from http://redesignresearch.com/chi05/EC\%20Boundary\%20Objects.pdf (Accessed, November 2007).

Cope, B. \& Kalantzis, M. (Eds) (2000) Multiliteracies: literacy learning and the design of social futures. London: Routledge.

De Corte, E. (1999) On the road to transfer: an introduction, International Journal of Educational Research, 31, pp. 555-559.

Edwards, R. \& Fowler, Z. (2007) Unsettling boundaries in making a space for research, British Educational Research Journal, 33(1), pp. 107-123.

Engeström, Y., Engeström, R. \& Karkkainen, M. (1995) Polycontextuality and boundary crossing in expert cognition: Learning and problem solving in complex work activities, Learning and Instruction, 5, pp. 319-336.

Goodman, R., Mannion, G. \& Brzeski, A. (2007) Reading, writing and resonance: an experiential workshop for practitioners, Research and Practice in Adult Literacy Journal, 61 (Special issue for RAPAL Conference 2006).

Hall, S. (1996) 'Introduction: Who needs ‘identity’? in P. duGay \& S. Hall (Eds) Cultural Identity. Thousand Oaks and London: Sage. 
Hodkinson, P. Biesta, G, \& James, D. (2008) Understanding Learning Culturally: Overcoming the Dualism Between Social and Individual Views of Learning. Vocations and Learning, 1, pp. 27-47.

Ivanič, R. (2004) Intertextual Practices in the Construction of Multi-modal Texts in Inquiry-based Learning, in N. Shuart-Faris \& D. Bloome (Eds) Intertextuality and Literacy in Clasrooms: Directions in Educational Research, pp. 275-310. Greenwich, CT.: Information Age Publishing.

Ivanič, R. (2007) Language, learning and identification, in: R. Kiely, P. Rea-Dickens, H. Woodfield \& G. Clibbon (Eds) Language, culture and identity in applied linguistics. London: Equinox.

Ivanič, R., Smith, J., Edwards, R., Mannion, G. \& Fowler, Z. (2004) Literacy practices as resources for learning: issues of identity, multimodality and fluidity, paper presented at the Annual Conference of the Teaching and Learning Research Programme, Cardiff, 22-24 November.

Ivanič, R., Edwards, R., Satchwell, C. \& Smith, J. (2007) Possibilities for pedagogy in further education: harnessing the abundance of literacy, British Educational Research Journal, 33(5), pp. 703 - 721.

Ivanič, R., Edwards, R., Barton, D., Fowler, Z., Mannion, G., Miller, K., Satchwell, K., Smith, J. (Eds) (Forthcoming 2009) Improving Learning in College: Rethinking literacies across the curriculum. London: Routledge.

Kress, G. (2001) '"You've Just Got to Learn How to See": Curriculum Subjects, Young People and Schooled Engagement with the World', Linguistics and Education, 11(4), pp. 401-415.

Kress, G. (2005) Gains and losses: New forms of texts, knowledge, and learning. Computers and Composition, 22(1), pp. 5-22. 
Kress, G. \& Van Leeuwen, T. (1996) Reading Images: The Grammar of Visual Design. London: Routledge.

Lave, J. (1996) The Practice of Learning, in S. Chaiklin \& J. Lave (Eds)

Understanding Practice: Perspectives on Activity and Context. Cambridge: Cambridge University Press.

Leander, K. M. (2002) Situated literacies, digital practices, and the constitution of space-time. Paper presented at the National Reading Conference 52nd Annual Meeting, Miami.

Lobato, J. (2003) How design experiments can inform a rethinking of transfer and vice versa, Educational Researcher, 32(1), pp. 17-20.

Mannion, G. (2006) Viewpoint: Striking a chord, Broadcast, 71, pp. 40-41. Available from http://www.sfeu.ac.uk/broadcast/broadcast 71 (accessed November 2007).

Mannion, G. \& Ivanič, R. (2006) Mapping literacy practices: theory, methodology, methods, International Journal of Qualitative Studies in Education, 20(1), pp. $15-30$.

Marsh, J. (2003) One Way Traffic? Connections between literacy practices in the home and in the nursery, British Educational Research Journal, 29(3), pp. 369382.

Millard, E. (2006) Transformative pedagogy: teachers creating a literacy of fusion, in K. Pahl \& J. Rowsell (Eds) Travel Notes from the New Literacy Studies, Instances of Practice. Clevedon: Cromwell Press.

Moll, L. C., Tapia, J., \& Whitmore, K. F. (1993) Living knowledge: The social distribution of cultural resources for thinking, in G. Salomon (Ed.), Distributed cognitions: Psychological and educational considerations, pp. 139-163.

Cambridge, UK: Cambridge University Press. 
Russell, D. R. (2005) Texts in contexts: theorizing learning by looking at literacies. Paper presented at ESRC Teaching and Learning Research Programme (TLRP) Thematic Seminar Series: Contexts, communities, networks: Mobilising learners' resources and relationships in different domains. Seminar Two, 15 June 2005, Lancaster University.

Satchwell, C. \& Ivanič, R. (2007) The textuality of learning contexts in UK Colleges, Pedagogy, Culture and Society, 15(3), Special Issue on Contexts, Networks and Communities, pp. 303-316.

Star. S. L. \& Griesemer. J. R. (1989) Institutional ecology, 'translations' and boundary objects: amateurs and professionals in Berkeley's museum of vertebrate zoology, 1907-1939, Social Studies of Science, 19, pp. 387-420.

Street, B. (1984) Literacy in Theory and Practice. Cambridge: Cambridge University Press.

Tuomi-Grohn, T. \& Engeström, Y. (Eds) (2003) Between Work and School: New Perspectives on Transfer and Boundary-crossing. London: Pergamon.

Tuomi-Grohn, T. \& Engeström, Y. (2003a) Conceptualising transfer: from standard notions to developmental notions, in T. Tuomi-Grohn \& Y. Engeström (Eds) Between Work and School: New Perspectives on Transfer and Boundarycrossing. London: Pergamon.

Usher, R. \& Edwards, R. (2007) Lifelong Learning - signs, discourses, practices. Dordrecht: Springer.

Van Oers, B. (1998) The Fallacy of Decontextualization, Mind, Culture and Activity, 5(2), pp. 35-142. 